\title{
Remedial Instruction in Language Disfluencies in the Non-Psycho-Expert Lens
}

\author{
Mick Mars P. Silvano, LPT, Maelt1, Evelyn C. Bandoy, LPT, EdD ${ }^{2}$ \\ ${ }^{1}$ Secondary School Teacher, ${ }^{2}$ Secondary School Principal \\ Buenavista National High School, Buenavista, Tandag City, Philippines
}

\begin{abstract}
This qualitative case study discovered and explored the plights of languages teachers conducting remedial instruction in language disfluencies, the way teachers conduct remedial instruction in language disfluencies in the non-psycho-expert lens, and the way learners progress in the kind of remediation they receive. The informants of the study were the language teachers of Buenavista National High School. These teachers are selected purposively as those who have encounter in remedial instruction for language disfluencies in the non-psycho-expert lens. The data were gathered through interviews with the informants. The study revealed that language teachers conducting remedial instruction in language disfluencies in the nonpsycho-expert lens face dire situations on insufficiency in terms of background knowledge on language disfluencies, time, and resources for remediation. Another problem that they face is the learner's attitude toward remedial instruction as well as parental or stakeholder support. Weak retention of the learners, insignificant change in the learning behavior and the use of colloquial words also contribute to the unwanted scenario of students undergoing remediation. Language teachers conduct remedial instruction in language disfluencies in the non-psycho-expert lens through utilizing various teaching strategies, going back to the basics, having awareness on learner diversity, seeking parental or stakeholder support, exemplifying passion for teaching, and having an encouraging class environment. Learners progress in such kind of remediation through the use of language in praxis or utilizing the communicative language teaching (by teachers) where students use language practically. Learners as well show activeness in the class knowing that they both share the same learning pace among peers. Most importantly, learners progress due to the acceptance and understanding of the teachers on the type of learners they have.
\end{abstract}

\section{KEYWORDS: remedial instruction, language disfluencies, teaching and learning}

\section{INTRODUCTION OF THE RESEARCH}

Remedial instruction is bound to accelerate learning for all as in the case of English as a language. The World Bank reports in 2012 that students from low income background fall behind early on their education journey. In the Philippines, the term remedial instruction is not foreign to teachers. It is a tutorial session given after a formal or structured teaching to assist slow performers improve their learning or mastery of a lesson when the result of achievement evaluation is below the expected level and therefore needs an extra step to reinforce learning. (Lanuzo and Magno 2016) DepEd Order No. 27, s. 2005 contains that the results of the national achievement tests for Grade 6 students indicate that a very large portion of those who enter high school have not yet mastered most of the elementary education curriculum and are unprepared for learning the secondary level curriculum. Need for remedial instruction early in the high school cycle for the least ready entrants remains substantial, urgent and essential. The Department of Education is, therefore, mandating that all public high schools shall organize and provide the following remedial instruction programs to increase the chances of having their students complete high school with sufficient mastery of its coverage.

Schwartz (2012) stressed that eventually, students who are lagging behind, will keep failing to learn the basic literacy and numeracy skills, and most likely will end up dropping out of school and remain illiterate. The importance of classroom-based language assessment and instruction is stressed by Falk-Ross (1996), as is the need for shifting the primary responsibility for special language intervention from the special educator alone to a shared collaboration of teacher, child, and language specialist. Collaboration between the language specialist and the classroom teacher was a notable feature in the study of Falk-Ross (2000:499:531). Changes in the nature of the student's language constructions and communicative competence, in the form of the teacher's supportive strategies, and in the speech or language pathologist's role in the classroom are foci, raising issues involving the procedures, problems, and promise for integrating language and literacy support programs involving students with language disorders into everyday classroom activities and pedagogic discourse routines. Hence, in finding the right remedy in instruction, Ratner (1995:180-6) mentioned that when children who stutter also demonstrate speech or language problems, establishing efficacious and reasonable therapy objectives can be difficult.

The National Achievement Test (NAT) for Grade 6 of the Department of Education conducted in Buenavista National High School (BNHS) for School Year 2017-2018 reveals those learners as having low proficiency in English Problem Solving Skills, Information Literacy Skills, and Critical Thinking Skills. Despite the notable efforts of teachers in the conduct of remedial instruction in English subject, it has been noticeable that the level of proficiency remains consistent as low. Hence, language teachers see language disfluencies as one great barrier to the mastery of the competencies in English. In the desire to eliminate language disfluencies, English teachers now conduct remedial instruction not just in English concepts but in Language Disfluencies which is seen as the key to effectively master the competencies. There lies the problem on giving remedial 
instruction in language disfluencies in the non-psychoexpert lens. Furthermore, the NAT for Fourth Year in the School Year 2014-2015 in BNHS also reveals that takers in the area of English fall under below average having $18.58 \%$ in the quartile distribution of scores while $1.77 \%$ was classified as poor.

This study describes and discovers the collective case of language teachers conducting remedial instruction in language disfluencies in the non-psychoexpert lens. Using the qualitative research design and case study as its approach to inquiry, the study looks into the remediation in language disfluencies as an event and a process for language teachers who are not psychoexperts but are attempting to correct language disfluencies in their own beliefs. The study hopes to point out effective measures in giving the right remedy to disfluencies.

\section{LITERATURE REVIEW}

This part of the proposed action research examines relationships between existing and relevant literatures deemed necessary to grasp better understanding along the course of this investigation.

The study of Goddard and Tuchscherer (2009:5-11) showed that the Running Waters Cree Nation, seeking speech and language services for children in the locally controlled school system, really hired psycho-experts to ensure they are giving the right diagnosis to the needs of the children. In fact, the investigation of the authors in meeting the speech and language needs of first nation's children attending bandcontrolled schools in Northern Saskatchewan, Canada resulted to having a contract with a team of speech or language pathologists who were able to demonstrate that the provision of long distance service is not without possibility. Notable in the favorable outcomes of the venture included the provision of ongoing funding, enhanced teacher knowledge, and the hiring of a qualified speech or language pathologist for the Woodlands Tribal Council, which serves 12 First Nations in the northern region of Saskatchewan, Canada.

In the investigation of Schunk and Rice (2014:49-54), the effects of strategy self-verbalization on children's selfefficacy and listening comprehension is that children with language deficiencies in grades two through four received instruction in listening comprehension while one-half of the children in each grade verbalized explicit strategies prior to applying them to questions. The strategy self-verbalization during remedial listening comprehension instruction led to higher self-efficacy across grades, and promoted performance among third and fourth graders, but did not benefit second graders. This tells us that language teachers may not be able to hit the right remedy in giving remedial instruction in the non-psycho-expert lens particularly in language disfluencies. Researchers recommend that future endeavor shall apply strategy self-verbalization to other language skills and shall explore the effects of covert fading.

Relatively, the study of Wolbers, Dostal and Bowers (2012:19-38) found that students, whether high or low achieving, demonstrated statistically significant gains with writing length, sentence complexity, and sentence awareness. The authors used a repeated-measures analysis of variance with a between-subjects variable for literacy achievement level to examine gains over time and the intervention's efficacy when used with students of various literacy levels. Strategic and Interactive Writing Instruction (SIWI) was used by the authors as the intervention in studying deaf students that are rarely, if ever, have nonstandard grammatical forms, seen in the writing of hearing students. This of course is seen to surely succeed since the remediating teachers are certain of the case and disorder of the learners. Hence, they exactly know what best intervention can be given to the learner.

On the other hand, the descriptive study of Allington, Stuetzel, Shake, and Lamarche (2010:15-30) on remedial reading instruction conducted in five classrooms in four different school districts was observed over a six-month period of time. In the observation of the researchers, a remedial instruction evolved. The said remediation consisted primarily of students completing skill lessons in workbook or worksheet activities with the teacher serving as a manager. True to the cases of language teachers conducting remedial instruction, they also utilize multifarious instructional materials such as workbooks and worksheets which were also used in the study of the researchers mentioned above just to satisfy and guarantee the delivery of remedial instruction in language disfluencies even in the non-psycho-expert lens.

The role of the teacher in the recently mentioned study only offered little direct instruction but distributed and corrected academic work. Unfortunately, most remedial activities were not congruent with classroom tasks. This is what is to be investigated by the current action research proposal. It is possible that language teachers may be offering remedial activities which are not congruent with classroom tasks because teachers are not certain about the language disfluency that the learner really has. Hence, remedial students generally received no additional instruction time to require reading behaviors. Therefore, only a small amount of the remedial instructional time was devoted to teacherdirected reading of connected text. In the researchers' study, the data were discussed within the framework of a general model of effective reading instruction. This is what usually happens with remedial instruction in the non-psycho-expert lens. Most language teachers only base the learning remedy within the framework of a general model but not from a psycho-expert's conclusion on language disfluency.

Language disorders are uneasy to understand, much more to identify from learners. In the study of Ness and Southhall (2010:36-43), preservice teachers held basic understanding of dyslexia as a reading disorder but they expressed confusion and misunderstanding about the specific phonological processing components of dyslexia. Authors suggested improving preservice teacher education regarding dyslexia. Hence, the scenario is very common among language teachers. They may have confusions and misunderstanding about language disorders. Therefore it is possible that language teachers may at times be giving the wrong remedy given the situation because these language teachers are not psycho-experts and that only very few have background on psycholinguistics, perhaps those who are earning doctorate degrees in English Language Teaching for instance.

Bear (1985:17) in his study on disfluent oral reading and spelling development stressed that the development of fluency in beginning readers is a gradual process that often 
involves different oral strategies such as word-by-word reading, pointing to words, and reading aloud to oneself. However, in the current study, it is being posited that any language teacher may find remedial instruction unsuitable for learners especially if the language teacher is not a psycho-expert. S/he may not be able to identify and conclude what language disfluency the learner has for him or her to be able to find the right remedy as for oral reading and spelling development in the study of Bear. He added that a review of research related to these behaviors and to corresponding spelling behaviors suggests a number of implications for instruction, including the following: (1) disfluent oral readers may need to point as they read, (2) reading in groups should be oral for beginning readers, (3) reading rate is a reliable and easily obtained indicator of fluency and is closely related to reading accuracy, and (4) diagnostic teaching should include a sampling of invented spellings and an analysis of the synchrony between stages of reading and spelling. Bear further noted that both fluency and expression can be promoted through the use of relatively easy material. Bear only emphasized easy material since it is true to the idea that teachers conduct remedial instruction on language disfluencies only in the non-psycho-expert lens.

Ehsani and Knodt (1998:54-73) also examined speech technology in computer-aided language learning, its strengths and limitations as a new call paradigm. The authors ended at drawing conclusions on the review of applications to identify directions of future research that might improve both the design and the overall performance of voice-interactive call systems. This also relates to the current undertaking that opts to identify future research that might improve the diagnosis in the conduct of remedial instruction for language disfluencies as employed by language teachers without professional conclusion on the disfluency of the learner.

The use and combination of suggested principles may also help teachers create fluency activities that meet their individual classroom needs. It was stressed by Rasinski (1989:690-3) in the study entitled Fluency for everyone: Incorporating fluency instruction in the classroom. In the case that language teachers partially conclude that a certain learner has certain language disfluency, the teacher provides various fluency activities just to be able to satisfy what the teacher feels the learner needs to have. Rasinski further stressed that most basal reading programs give little recognition to fluency as an important goal, and that few reading textbooks for prospective teachers provide an indepth treatment of the topic. However, the depth of giving treatment of the topic can only be fathomed if the teacher knows what exactly is the professional psychological diagnosis of the learner in terms of language disfluency before going through remedial instruction.

Rasinski further noted that reading fluency often becomes a salient issue only when students demonstrate significant deficiencies (p. 690). In the case of remediation, not all language disfluencies has to be evident with significant deficiencies but it is the way how teachers know that they have disfluencies; always true in the non-psycho-expert lens. The students then are often referred to corrective or remedial classes where they finally receive special instruction in the development of fluent reading. This is what happens especially to language teachers. The only basis of language teachers is the learner's demonstration of significant deficiencies and later on coming into conclusion that the learners has this certain language disfluency.

In the teaching of fluency to students, Rasinski has cited the following as methods which have been proven successful: repeated readings (Dowhower 1987; Herman 1985; Samuels 1979), reading while listening or echo reading (Carbo 1978; Chomsky 1976; Gamby 1983; Laffey and Kelly 1981; Schneeberg 1977; Van Der Leij 1981), the neurological impress method (Heckelman 1969), and reading in phrases (Allington 1983; Amble and Kelly 1970; Gregory 1986). Notice the study of Heckelman, it is a neurological impress method which is so designed for a certain language disfluency in a psycho-expert lens. Finally, Rasinski also mentioned that teachers who wish to make fluency instruction an integral part of the regular reading curriculum may be at a loss in attempting to use corrective fluency methods in a way that is appropriate for the more normal reader.

\section{RESEARCH QUESTIONS}

This qualitative research having case study as its approach to inquiry seeks to answer the following research questions:

1. What are the plights of language teachers conducting remedial instruction in language disfluencies?

2. How do language teachers conduct remedial instruction in language disfluencies in the non-psycho-expert lens?

3. How do learners progress in a remedial instruction in language disfluencies in the non-psycho-expert lens?

4. What can be a proposed intervention based on the findings of this case study?

\section{SCOPE AND LIMITATION}

This basic research discovers and describes the phenomenon on language teachers giving remedial instruction in language disfluencies as non-psyco-experts. The study deals with the cases of (1) teachers, particularly language teachers, who conduct remedial instruction in language disfluencies in the non-psycho-expert lens and (2) learners who receive the instruction and how they progress. It is limited only to generally describing the phenomenon of teachers' belief on the disfluency learners have and vice versa on the learners' uncertainty or even unconsciousness and unawareness of their disfluency. The study does not deeply focus on certain disorders teachers believe learners to have but only on the phenomenon of teachers and learners who are in the process of teaching and learning in the non-psycho-expert lens since language disfluencies require a lot of psycholinguistics.

The phenomenon studied is that of Buenavista National High School in the City Division of Tandag.

\section{RESEARCH METHODOLOGY}

This part of the research presents how the study went through the sampling of informants, and the collection of data from the informants.

\section{Sampling}

The study purposively selected informants qualified through a set of criteria. To Crossman (2018), purposive sampling is a non-probability sample that is selected based on characteristics of a population and the objective of the study. Purposive sampling is also known as judgmental, selective, or subjective sampling.

The set criteria for the informants were the following: (1) a language teacher who holds language subjects (particularly 
English), (2) one that conducts remedial instruction in language disfluencies, and (3) one that submits himself/herself as a language teacher non-professionally identifying language disfluencies on learners and thus, conducts remedial instruction on the disfluencies in the nonpsycho-expert lens or without less or enough background on psycholinguistics. In order to best serve the purpose of the study, these criteria to qualify the informants are hereby set.

\section{Data Collection}

Since a case study method involves using multiple sources and techniques in the data gathering process according to Soy (1997), there is a need to determine in advance what evidence to gather and what analysis techniques to use with the data to answer the research questions.

Inspired by Soy, this case analysis, which is normally and largely qualitative, used interviews, documentation review, observation, and even collected physical artifacts as tools in the collection of data as it sought to answer the research questions.

\section{DISCUSSION OF RESULTS AND RECOMMENDATIONS}

This part of the research presents the results, interpretation, and analysis of the data gathered in this study. Implications of the study, its outcomes, as well as concluding remarks are also included in this section.

After our interview with the research informants, we were able to develop themes under each concept as answers to the research questions.

\section{Plights of Language Teachers Conducting Remedial} Instruction in Language Disfluencies

From the informants' responses, the following are their plights in the conduct of remedial instruction in language disfluencies in the non-psycho-expert lens. These are expressed in the following themes: insignificant change, weak retention, learners' attitude toward remedial instruction, insufficiency, and colloquial words as well as parental/stakeholder support.

Insignificant Change: Language teachers expressed that there seem to be no significant change in the learning of students after remedial instruction is given. There is no change in behavior after learning is being offered by the concerned teachers after remedial instruction. Learners do not understand and/or comprehend the text they are reading. (KII1, KII11)

As one informant said, "The learner is still the same. We do remediation but there seem to be no change in them. Actually, your purpose of remediation is just to let the learner pass. It's not really remedial instruction because it's still the same." (KII11)

Villanca (2016) concluded that differentiated instructional plan is proposed and designed to help teachers enhance their learning activities while considering as well the learning style of their pupils in the class. This may aid in ensuring to have a significant change in the learning development or progress of learners who undergo remedial instruction in language disfluencies under the non-psychoexpert lens.
Weak Retention: Weak retention of the learners is one of the struggles of language teachers who do remedial instruction in language disfluencies in the non-psychoexpert lens. The informants expressed that the learners' retention is really weak as that of the novice learners. As a result, teachers tend to subsequently think and believe that the learner is a novice one. Learners strive to accommodate instruction and the lesson as a whole. Sometimes teachers kid that these learners will learn over 20 years which means that it would really take time. (KII2, KII12)

As one informant describes a learner who undergoes remedial instruction, "Has low vocabulary which greatly contributes to weak retention." (KII2)

This is negating the study of De Leon (2013) in which $72 \%$ of the assessed learners obtained a passing rate in the final after the Student Learning Circle Program has been implemented. The program is designed as an assessment for improved students' scholastic performance and retention.

Learners' Attitude Toward Remedial Instruction: According to our interview with the informants, learners who undergo remedial instruction submit themselves to such instruction due to the thinking that they might fail in the subject if they don't comply. However, learners only comply complimentarily. No matter how low his or her scores are, it won't matter to the learner so long that he/she is undergoing remedial instruction or is attending such. There is still eagerness to learn only out of the thinking that he/she may fail if he/she won't do such things required of him/her in the duration of the remedial instruction. (KII14, KII13, KII15, KII9, KII63, KII37)

As one informant shares, "The leaners' negative attitude toward remedial instruction is a great barrier to effective remedial teaching. Their lack of motivation to learn is the hindrance in learning the language." (KII9)

Students under remedial instruction class in language disfluencies are not interested in learning for they lack motivation to learn the language and they have difficulty in understanding what is being taught.

Irimia (2016) posits that language learning is vital in the early stages of a child's learning development. It is in these stages that the foundations of lifelong language learning are laid. Further, it plays a vital role in ensuring that our children and young people develop the correct attitudes towards learning other languages and exploring cultures other than their own. Learners who undergo remedial instruction perhaps are those who were not able acquire a set of competencies expected for a particular stage in language learning. Hence, as they go to higher levels, they find it hard to understand concepts due to the lack of content mastery in learning higher and complex concepts about language.

Insufficiency: Four insufficiencies are expressed by the informants. These are insufficiencies on (1) the experience of teachers on attention-getting, (2) the time for teachers to prepare instructional materials, (3) the availability of resources just like internet connectivity, and (4) the lack of trainings. Some of the language teachers has insufficient experience when it comes to catching the attention of learners especially that these students have difficulty sustaining their interest in listening and participating in the 
discussion. Teachers also suffer insufficient time to prepare teaching materials because of the school activities and the reports that teachers must comply within a rush time duration. (KII8, KII10, KII6, KII7, KII38, KII39, KII40, KII41, KII42)

One informant said, "There are limited resources when it comes to the available materials used in remedial teaching and also the internet connectivity in which the connection is sometimes interrupted maybe because of the location and area from where the school is situated." (KII8)

The lack of trainings and other relevant seminars or workshops among teachers who conduct remedial instruction in language disfluencies as well contribute to the problems faced by language teachers in giving optimum learning to students. Their limited knowledge about language disorders and disfluencies affect the way they teach and design the lesson for struggling learners who usually are lagged behind. As a result, here also comes the insufficiency on knowledge about remedial teaching strategies for treating language disorders and disfluencies as a very essential factor in language teaching.

The study of Hamaybay (2008) affirms to this result. The finding of the study revealed that the teaching performance of the respondents improved from $92.03 \%$ to $93.17 \%$ after teachers have undergone external faculty development training program on teaching effectiveness. Hence, the T-test results also revealed that the external faculty development trainings or programs played a significant impact on teaching effectiveness.

Colloquial Words: The informants also shared about their encounter of learners who use colloquial words even in academic papers or any other school requirements. Some of the students do not know the right spelling of the words. Instead, they are using the spellings usually seen in text messaging and social networking. These are evident in their written outputs just like essays, among others. (KII3, KII4)

As an informant stressed, "Colloquial words are also present maybe because of the influence of media communications." (KII4)

This problem faced by teachers as evidenced by students' outputs is complemented by a semiotic analysis of five news stories in the Philippine Daily Inquirer and Philippine Star (Reyes, Galdo, Mabandus, Mojica, \& Carvero:2012). In the analysis, the complacent use of figurative or colloquial expressions can distort the real score of the event. It can portray a different scenario compared to what really happened. Comparatively, the use of colloquial words by students undergoing remedial instruction can also affect their comprehension knowing that these words could distort the meaning of certain expressions or utterances both in written and oral form.

Parental/Stakeholder Support: For the language teachers who conduct remedial instruction in language disfluencies in the non-psycho-expert lens, one of the problems encountered is the absence of parents'/stakeholders' full support. Learners and teachers are the focus of learning but parents are the most important stakeholders. This means that parents or stakeholders contribute to effective learning if for instance children are properly guided, prepared, and nourished at home. Giving them the basic needs at home would mean that proper nourishment is one of the factors

that contribute much to sustaining good study habits and the readiness and capacity to learn. (KII43, KII44) As one informant said,

"I therefore conclude that every stakeholder embedded in the wholesome learning of the child gives a significant contribution in the attainment of quality education. The learner is an integration of the social collaboration of the different stakeholders that mold students with better learning." (KII44)

Olguin and Keim (2009) stressed that the use of stakeholders can be career bridges to the advancements of students' academic performance. This supports the claim of the study that the involvement and support of parents and all other stakeholders is vital to the learning development and progress of every learner.

Teachers' Way of Conducting Remedial Instruction in Language Disfluencies in the Non-Pyscho-Expert Lens After our interview with the informants, we identified they ways teachers conduct remedial instruction in language disfluencies in the non-psycho-expert lens through the following themes: variety of teaching strategies, going back to the basics, awareness on learner diversity, parental/stakeholder support, passion for teaching, and encouraging class.

Variety of Teaching Strategies: Most of the informants shared that one of the things they do in the remediation is working on the different techniques and strategies to teach these types of learners. This would also mean that it needs extra effort to exhaust everything just to make them learn. They also posit that a language teacher shall exude more effort to become resourceful so that more ideas could equip the mentor to teach learners in the remediation. As many of the teachers adhere to, "We cannot give what we do not have." (KII46, KII51, KII52, KII69, KII76, KII78, KII26, KII27) One of the informants share,

"One-on-one teaching is also recommended for a teacher especially in teaching a student how to read. There are students who feel more comfortable and relaxed when they are taught alone. Without the presence of other classmates would mean privacy for them. This will help them learn better." (KII51)

Peer tutoring also gives a big impact to learning. There are learners who feel comfort in learning when paired to a buddy. They cooperate more because they feel their buddy feels the same how they feel too (KII52).

This is supported by the study of Wilson and Gerber (2008:29-44) that offered a variety of teaching strategies of which some arose from their own primary research in investigating how Generational Theory can improve teaching and the strategies for working with the millennials.

Going Back to Basics: Informants shared that one significant solution to teach or conduct remedial instruction is to let the learners have the basic skills in language learning. A building would collapse without firm or stable framework. Thus, a complex concept would be very difficult 
for a student whose basic skills were not properly addressed (KII49, KII50, KII77, KII15, KII16, KII17, KII28). One informant said,

"Ifyou need to teach the alphabet sounds, CVC pronunciation, syllabication, and even letter writing, do it and pursue for this would become the starting point of a student to adopt the tremendous challenges to learn the language." (KII50)

There is even a need to refresh the basic use of a sentence and how they are constructed (KII77).

This is in consonance to the study of Kunzell (2014) that the mind's basic task is to organize adaptive behavior. He argued that necessary conditions to achieve this are acquiring a body-self, a differentiated perception, motor intuition, and motor control. Moreover, the latter three can be learned implicitly by crosswise comparing the perceived actual situation, the desired situation, the perceived result and the anticipated result.

Awareness on Learner Diversity: First thing that a teacher should do is to know the types of learners inside the classroom. The teacher should be able to distinguish the expert, average, and novice learners. Students inside the classroom may be arranged according to learner typology. Through this, the teacher can easily identify what strategies and instructional materials are best needed and are best suited for such learners (KII45, KII67, KII25).

"Language teacher conducts remedial instruction in language disfluencies in the non-psycho-expert lens through evaluation of the different learners he/she handles." (KII67)

In the teaching preparation, the remedial teacher should identify the students' diverse needs especially in language learning (KII25).

In the self-assessment of self-directed learning and issues of learner diversity of Thomson (nd), he claimed that learners are born self-directed. Young ones know how to take charge of their own learning. The self -assessment project was innovative for the large number of learners and the diversity of learner population.

Parental/Stakeholder Support: If possible, a language teacher may also meet the parents of the learners for them to assess what the weaknesses of their children are at home that shall be catered or addressed well (KII53, KII54).

"Meeting the parents would mean that partnership will bring out possible solutions to how why learners have difficulty to learn language." (KII53)

Language teachers will have adequate background about the child and subsequently will understand the difficulty reasons of the learners and as well be able to make necessary and appropriate preparations for the remediation session (KII54).

Even in online learning, there is a challenge posed by collaboration. In the study of Thorpe (2002), there is a need to rethink of learner support. Learner support is integral. Learner support plays a key role in the development of a learner.
Passion for Teaching: It is deemed that a teacher who holds remediation has a big heart for teaching. It is not the ordinary teaching with ordinary learners but teaching the

kinds of learners subjected to remedial classes in language disfluencies. If the teacher has this surmounting passion, no barrier, conflict of schedule, worries, or rainy days could stop him/her in molding these learners because he/she believes that in his/her big heart to teach lays the responsibility to teach (KII55, KII32).

\section{"Show concern for the performance of the students." (KII32)}

Students may encounter different problems in their studies. Therefore, remedial teachers shall carefully observe the learning process of each student in the remedial class. Whenever necessary, teachers shall provide individualized remedial teaching for language before and after the remediation class so that they can remove the learning obstacles as soon as possible and meaningful learning of the language will be achieved (KII32).

Day (2004:12) in his book Passion for Teaching stressed, "To be passionate about teaching is not only to express enthusiasm but also to enact it a principled, values-led, intelligent was... Passion is associated with enthusiasm, caring, commitment, and hope which are themselves key characteristics of effectiveness in teaching."

Encouraging Class: Teachers conduct remedial instruction in language disfluencies in the non-psycho-expert-lens by enhancing the learning interest of the students as well as sustaining their motivation (KII29, KII30).

"Students who suffer frustrations in their learning difficulties, family problems, and other emotional and physical issues may lost their interest in learning the language." (KII29)

Hence, teachers shall implement the curriculum in a way that it caters the needs of the students in learning the language (KII29). There is a need to encourage active participation among students in the remediation process. Students with difficulties in learning language usually lack self-confidence and are more passive in the class. They seldom ask questions or express their views. They doubt in their participation in the class. Teachers who conduct remedial instruction in language disfluencies shall patiently encourage active participation in the class. Pleasurable learning experiences may help enhance students' interest in learning the language (KII30).

This affirms on the study of Wolbers, Dostal, and Bowers (2012:19-38) where the informants exemplify encouragement in the remediation and later found that students, whether high or low achieving, demonstrated statistically significant gains with writing length, sentence complexity, and sentence awareness.

\section{Learners' Progress in Language Disfluencies Remedial Instruction in the Non-Psycho-Expert Lens}

Being Active in the Remediation: Learners in language disfluencies remedial instruction in the non-psycho-expert lens progress through being active in the course of the remediation. Learners are motivated to participate and they interact positively toward the discussion of the topic (KII34, KII83, KII81, KII84, KII82). As one informant said, 
"The students can now have confidence to participate during the remedial class." (KII81)

Learners in remedial instruction cooperate in whatever activities are given by the teachers (KII83). Students also exhibit positive thinking, "If others can, why can't I?" (KII84)

This is relevant to the study of Goddard and Tuchscherer (2009:5-11) which showed that the Running Waters Cree Nation, seeking speech and language services for children in the locally controlled school system, really hired psychoexperts to ensure they are giving the right diagnosis to the needs of the children. When learners receive the right diagnosis in the course of remediation, then no wonder, they exhibit a level of activity in the remedial instruction.

Use of Language in Praxis: Learners also progress in language disfluencies remedial instruction in the nonpsycho-expert lens by way of immersing themselves in the use of language and through teachers' employment of communicative language teaching. Learners progress through using the language naturally in the communicative activities set out by the remedial teacher (KII33, KII35, KII75).

"Talk to students in English and encourage them to use the language inside and outside the classroom and then give them rewards." (KII75)

This kind of motivation may help in ensuring progress in remedial instruction in language disfluencies (KII75). The learners also improved in terms of their communicative competencies and their ability to use language interactively (KII33). Students' language disfluencies will be minimized if not eradicated. In terms of erroneous speech in language production, students learn to speak without any interruptions (KII35).

This affirms the investigation of Schunk and Rice (2014:4954 ) in which the strategy self-verbalization, which is a communicative language strategy, led to higher self-efficacy during remedial listening comprehension instruction. It promoted performance among third and fourth graders though did not benefit the second graders.

Teachers' Acceptance and Understanding of Learners: Teachers play a key role in ensuring progress of learners undergoing remedial instruction in language disfluencies in the non-psycho-expert lens. Through their acceptance and understanding of the kind of learners they teach in remediation sessions, these learners are able to withstand the difficulties they are experiencing in the learning process (KII20, KII21, KII22).

So far, the problems of students do not only dwell upon reading. There are also problems in pronunciation but teachers try to consider and understand the learners' situations (KII20). As one informant shared,

"It is not new that most of them are really struggling. They find it very hard to construct even just a sentence. For example of they have an assignment, an essay for instance, ohmygod, I feel like I must have been the writer of the essay due to the many corrections that I have to write in their papers. I then write encouraging remarks at the bottom of their papers. In one section, there are only around two or three who can at least execute a sort of competence. Then I have to say "Very good! Hope to read more from you." (KII21)

Teachers have no choice but to accept the reality that these are the kinds of learners they have to deal with (KII22).

Fenwick and Tennant (2004:55-73) noted in their book entitled Dimensions of Adult Learning: Adult Education and Training in a Global Era that the understanding of adult learning process has undergone dramatic changes over the past few decades. The authors also have noted new theories informing adult learning to continue to appear, existing theories get attacked or reinvented, while educators must wonder where, amid all the argument, lies the best approach for their practice. There is no best way to understand learning, just as learners and educators are each very different and constantly changing. It would imply that learners who undergo remedial instruction in language disfluencies in the non-psycho-expert lens share the same characteristics as the adults in their learning. Each is very different and is constantly changing. Hence, there is really a need for teachers to wholeheartedly accept and understand them the way they are.

Proposed Intervention Based on the Findings of the Study

Primarily, this qualitative case study implies that the Department of Education may consider hiring clinical professionals to diagnose learners about their cases so teachers would be able to give the right remediation. These clinical professionals may be psychologists, psychiatrists or speech pathologists. The possible implementation of this proposed intervention based on the results of this case study can be best done in the elementary level since it lays the foundation skills of the child namely literacy and numeracy. It would be harder for teachers to remediate in the secondary level when the child's readiness and capacity do not correspond to the learning competencies set out for secondary level. Hence, the diagnosis of children's language disfluencies or disorders by pyscho-experts is very necessary to ensure language proficiency among learners. Moreover, language proficiency is of much importance. It is pre-requisite to the comprehension of other subject areas since it is the medium of instruction.

Based on the findings of the study, it is deemed important that an orientation on Language Disorders/Disfluencies among Language Teachers conducting remedial instruction in language disfluencies in the non-psycho-expert lens be conducted to effectively suit the specific needs of learners who struggle in language learning due to their disfluencies. These disfluencies are not properly addressed due to the poverty of schema of the language teachers regarding language disorders or disfluencies.

The orientation may hire a professor in applied linguistics to discuss such matter. Knowing that language disorders are those problems that involve processing of linguistic information such as grammar or semantics, the orientation is necessary so that language teachers can effectively design remedial instruction according the common characteristics of language disorders learners show or possess.

These problems can be receptive problems just like language comprehension or expressive problems just like language production. Language disorders affect both written and 
spoken language. Hence, when not addressed properly even during the remediation, then it can be disastrous to teachers treating the learners not in the way they should learn.

Linguists affirm that most language disorders appear in early ages and they should be treated as soon as possible. This is the reason why teachers find it hard in the secondary level remediation to achieve competence among learners who use the language. They are produced in neurological and cognitive areas.

As Dale Carnegie stressed, "There are four ways, and only four ways, in which we have contact with the word. We are evaluated and classified by these four contacts: what we do, how we look, what we say, and how we say it."

\section{Recommendations}

Based on the results of the case study, the following are hereby recommended:

1. The Department of Education may hire clinical professionals to diagnose the emerging cases of language disfluencies among learners for teachers to effectively employ their remediation to these types of learners.

2. For the School, Division, Region, or Department of Education to conduct orientation about language disorders/disfluencies among language teachers employing remedial instruction in language disfluencies to further improve the efficiency and efficacy of the remediation.

3. That the school shall have close monitoring and evaluation on the conduct of remedial instruction to track progress of learners not proficient in language leading to a decreased drop-out rate of the school as well on the percentage of frustration level in reading.

\section{DISSEMINATION AND ADVOCACY PLANS}

Dissemination and utilization of research results are crucial in the achievement of learning outcomes, and improve teaching-learning and governance processes in schools, schools division officers, regional offices, and central office. (DepEd Order No. 16, s. 2017)

Hence, once the research is completed, the following plans for dissemination and advocacy shall be considered:

1. Publication of the Completed Research in a Reputable International Journal

2. Possible presentation of the Completed Research in a Research Conference or Forum

3. Furnishing of Copies of the Completed Research to the Research Informants and all other Language Teachers and interests others

4. Inclusion of the Completed Basic Research in the School Learning Action Cell

5. Recommending to the School Head through the INSET Coordinator to possibly include the research results in the training design and how these can be utilized

6. Presentation of the Research Results and proposed actions during school planning and monitoring activities

7. Incorporation of the research results in the Enhanced School Improvement Plan or Annual Implementation Plan

\section{REFERENCES}

[1] Anally A. Villanca. "Pupils Learning Styles: Basis For An Enhanced Teachers' Differentiated Instructional Plan In English." LAMDAG 7.1 (2016). Web. 17 May 2017.
[2] Bear, Donald R. "Disfluent Oral Reading and Spelling Development." Center for Civic Innovation, Manhattan Institute for Policy Research. 52 Vanderbilt Avenue, New York, NY 10017. Tel: 212-599-7000; Fax: 212599-3494; Website: htpp://www.manhattaninstitute.org, 30 Apr. 1985, eric.ed.gov/?id=ED280015.

[3] Crossman, Ashley. "What You Need to Understand About Purposive Sampling." Thought Co, Thought Co, 1 Apr. 2018, www.thoughtco.com/purposive-sampling3026727.

[4] Dale H. Schunk \& Jo Mary Rice (1984) Strategy SelfVerbalization During Remedial Listening Comprehension Instruction, The Journal of Experimental Education, 53:1, 4954, DOI: $10.1080 / 00220973.1984 .10806361$

[5] Day, Christopher. A passion for teaching. Routledge, 2004.

[6] Ehsani, Farzad. "Speech Technology in Computer-Aided Language Learning: Strengths and Limitations of a New Call Paradigm." Language Learning \& Technology, vol. 2, no. 1, July 1998, pp. 54-73., www.lltjournal.org/.

[7] Gen-gen 0. Hamaybay. "Impact Of External Faculty Development Training Program On Teaching Effectiveness." TIP Research Journal Quezon City5.1 (2008). Web. 06 April 2016.

[8] Falk-Ross, Francine. "Classroom-Based Language Remediation Programs: Roles, Routines, and Reflections." Center for Civic Innovation, Manhattan Institute for Policy Research. 52 Vanderbilt Avenue, New York, NY 10017. Tel: 212-599-7000; Fax: 212599-3494; Web Site: Http://Www.manhattanInstitute.org, 23 Feb. 1996, eric.ed.gov/?id=ED417539.

[9] Fenwick, Tara, and Mark Tennant. "Understanding adult learners." Dimensions of adult learning: Adult education and training in a global era (2004): 55-73.

[10] Irimia R, Gottschling M (2016) Taxonomic Revision Of Rochefortia Sw. (ehretiaceae, Boraginales). Biodiversity Data Journal 4: E7720. Https://doi.org/10.3897/bdj.4.e7720

[11] J. Tim Goddard \& Maria Tuchscherer (1997) Meeting the speech and language needs of first nation's children attending band-controlled schools in Northern Saskatchewan, Canada, Australian Journal of Learning Disabilities, $2: 4,5-11$, DOI: $10.1080 / 19404159709546543$

[12] Kunzell, Stefan. "Learning the Basics." Reserarch Gate, Apr. 2000 , www.researchgate.net/profile/Stefan_Kuenzell/public ation/227344709_Learning_the_basics/links/0fcfd500 13a8637640000000.pdf.

[13] Lanuzo, Roselyn and Gerardi 0. Magno. "Remedial Teaching in the Philippines." TeacherPH, Mark Anthony Llego, 15 May 2016, www.teacherph.com/remedialteaching-in-the-philippines/.

[14] Nelly D. De Leon. "“Student Learning Circle” Program: Assessment for Improved Students' Scholastic Performance and Retention." Journal of Business, Education and Law 17.1 (2013). Web. 02 December 2015. 
[15] Ness, Molly, and Gena Southhall. "Preservice Teachers' Knowledge of and Beliefs About Dyslexia."Journal of Reading Education, vol. 36, no. 1, 2010, pp. 36-43., web.b.ebscohost.com/abstract?direct=true\&profile=eh ost \&scope $=$ site \&authtype $=$ crawler\&jrnl $=08865701 \& A$ $\mathrm{N}=57311383 \& \mathrm{~h}=\mathrm{rGMTbUYHMuYeyQ6vYybrQ/9JACW}$ VG2PIYZUTaFYELj8RiSIoz/e9v6X41Z6FeOivm/0iVBnS Y1p9bVAQFBBhEQ $==\& \mathrm{crl}=\mathrm{c} \&$ resultNs $=$ AdminWebAut h\&resultLocal=ErrCrlNotAuth\&crlhashurl=login.aspx?d irect=true \&profile $=$ ehost $\&$ scope $=$ site \&authtype $=$ crawl er\&jrnl $=08865701 \& A N=57311383$.

[16] Olguin, David L., and Jeanmarie Keim. "Using Stakeholders as Career Bridges to Advance Students' Academic Performance: How Would You Like Your Stake?" ERIC, 2009, p. 22., eric.ed.gov/?id=EJ886136.

[17] Rasinski, Timothy. "Fluency for Everyone: Incorporating Fluency Instruction in the Classroom." The Reading Teachher, vol. 42, no. 9, May 1989, pp. 690693.,www.jstor.org/stable/20200275?seq=1\#page_sca n_tab_contents.

[18] Ratner, Nan Bernstein. "Treating the Child Who Stutters with Concomitant Language or Phonological Impairment." Language, Speech, and Hearing Services in Schools, American Speech-Language-Hearing Association, 1 Apr. 1995, lshss.pubs.asha.org/article.aspx?articleid=1780075.

[19] Reyes, Maria Elena C., Galdo, Mary Ann T., Mabandus, Reeham B., Mojica, Tizziana M., and Kirk R. Carvero. "A Semiotic Analysis of Five News Stories in the Philippine Daily Inquirer and the Philippine Star." Advancing Literature and Communication Research 1.1 (2012). Web. 14 January 2016.

[20] Richard Allington, Helen Stuetzel, Mary Shake \& Sharron Lamarche (1986) What is remedial reading? A descriptive study, Reading Research and Instruction, 26:1, 1530, DOI: $10.1080 / 19388078609557892$

[21] Roller, Margaret, and Paul Lavrakas. "Ethical Considerations in Case-Centered Qualitative Research." Research Design Review, 16 June 2016, researchdesignreview.com/2016/06/16/ethicalconsiderations-in-case-centered-qualitaive-research/.

[22] Schwartz, Analice C.. 2012. Remedial education programs to accelerate learning for all (English). Global Partnership for Education (GPE) working paper on series; no. 11. Washington DC; World Bank. http://documents.worldbank.org/curated/en/564671 468151507990/Remedial-education-programs-toaccelerate-learning-for-all
[23] Soy, Susan K. (1997). The case study as a research method. Unpublished paper, University of Texas at Austin.

[24] Mary Thorpe (2002) Rethinking Learner Support: The challenge of collaborative online learning, Open Learning: The Journal of Open, Distance and eLearning, 17:2, 105119, DOI: $10.1080 / 02680510220146887$ a

[25] Thomson, Chihiro K. "Taking Control." Google Books, Google,books.google.com.ph/books?hl=en\&lr=\&id=pT HxAQAAQBAJ\&oi=fnd\&pg=PA77\&dq=learner diversity\&ots=qr80-

UMEJb\&sig=xhROS_9q5UzcTWL8p6GtxptgZCw\&redir_ $\mathrm{esc}=\mathrm{y} \# \mathrm{v}=$ onepage $\& \mathrm{q}=$ learner diversity $\& \mathrm{f}=$ false.

[26] Wilson, Michael, and Leslie E. Gerber. "How Generational Theory Can Improve Teaching: Strategies for Working with the 'Millennials."' Currents in Teaching and Learning, vol. 1, no. 1, ser. 2008, pp. 2944. 2008,pdfs.semanticscholar.org/4aec/f98b4cd5c7da d19e27f1bd85d5befd3e3121.pdf

[27] Wolbers, Kimberly, et al. "I Was Born Full Deaf." Written Language Outcomes After 1 Year of Strategic and Interactive Writing Instruction | The Journal of Deaf Studies and Deaf Education | Oxford Academic." OUP Academic, Oxford University Press, 13 May 2011, academic.oup.com/jdsde/article/17/1/19/358246.

\section{FINANCIAL REPORT}

\begin{tabular}{|c|c|c|}
\hline $\begin{array}{l}\text { Item } \\
\text { No. }\end{array}$ & Particulars & Cost \\
\hline 1. & Hard Copy Paper A4 70 gsm & P266.75 \\
\hline 2 & Plastic Comb Binder Rings Spines & P199.00 \\
\hline 3 & LCT Premium Glossy Photopaper & P99.00 \\
\hline 4 & $\begin{array}{l}\text { Premium Dye Ink for Epson } \\
\text { Printer }\end{array}$ & P500.00 \\
\hline 5 & $\begin{array}{l}\text { A4 Size Anti-Slip PVC } \\
\text { Professional Cover }\end{array}$ & P376.00 \\
\hline 6 & $\begin{array}{l}\text { Snacks for Informants of the } \\
\text { Study }(10 @ 40)\end{array}$ & P400.00 \\
\hline 7 & $\begin{array}{l}\text { Publication in an International } \\
\text { Open Access Journal } \\
\text { (International Journal of Trend in } \\
\text { Scientific Research and } \\
\text { Development) }\end{array}$ & $\mathrm{P} 1,318.56$ \\
\hline & Total & P3, 159.31 \\
\hline
\end{tabular}

